\title{
Regimes reloaded! A reappraisal of Schumpeterian patterns of innovation, 1977-2011
}

\section{Roberto Fontana ${ }^{1,2}$ - Arianna Martinelli ${ }^{3} \cdot$ Alessandro Nuvolari $^{3}$}

Accepted: 18 May 2021 / Published online: 25 June 2021

(c) The Author(s) 2021

\begin{abstract}
One of the most significant results of the empirical literature on innovation studies of the 1980s and 1990s was that innovation patterns were characterized by important inter-sectoral differences. This finding prompted a lively research agenda that: i) provided empirical characterizations of sectoral patterns of innovation by means of taxonomic exercises; ii) sought to interpret sectoral patterns of innovation as emerging properties of underlying selection and learning processes reflecting the structural properties of technical change at sectoral level ("technological regimes"). In this paper, we reconsider one of the landmark works on technological regimes (e.g., Breschi et al. 2000), reassess its findings, and perform a quasi-replication of their its exercise. Our conclusion is that the proposed distinction between Schumpeterian patterns of innovation (Mark I vs. Mark II) and their interpretation in terms of technological regimes has still the promise of yielding important insights concerning on the connection between inventive activities and industrial dynamics.
\end{abstract}

Keywords Innovation - Patterns of innovation - Patents $\cdot$ Schumpeter Mark I and Mark II

JEL classification $\mathrm{O} 31 \cdot \mathrm{O} 33 \cdot \mathrm{O} 34$

Roberto Fontana

roberto.fontana@unipv.it

Arianna Martinelli

arianna.martinelli@santannapisa.it

Alessandro Nuvolari

alessandro.nuvolari@santannapisa.it

1 Department of Economics \& Management, University of Pavia, Via San Felice 5, 27100 Pavia, Italy

2 ICRIOS-Bocconi University, Via Roentgen 1, 20135 Milan, Italy

3 Scuola Superiore Sant'Anna, Istituto di Economia, Piazza Martiri della Libertá 33, 56126 Pisa, Italy 


\section{Introduction}

During the 1980s and 1990s a tremendous effort in the field of innovation studies has been devoted to the empirical characterization of sectoral patterns of innovation. This approach was prompted by the increasing availability of data on inventive activities (patents, research and development investment, etc.) at both sectoral and firm level which were suggesting that innovative activities display a wide degree of variety across industries along several dimensions, such as the knowledge base underlying innovation processes, the type of actors and institutions involved in innovative activities, the characteristics and the economic effects of innovations (Malerba 2005). In this context, the aim of taxonomic exercises was that of identifying, against the backdrop of an extremely variegated empirical evidence, some "ideal types" capable of capturing the key-dimensions along which innovative activities varied across industries. The two most popular distinctions put forward to characterize inter-sectoral differences in patterns of innovation were the Pavitt's taxonomy (Pavitt 1984) and the Schumpeter Mark I and Mark II regime 'dichotomy' (Malerba and Orsenigo 1995, 1996).

Relying upon detailed data on major innovations introduced in the UK between 1945 and 1979, Pavitt (1984) proposed the existence of four major profiles of innovative activities at sectoral level: i) supplier dominated sectors (industries in which innovations are, by and large, embodied in equipment and other capital goods and where the adoption of new technologies is often coupled with learning by using and learning by doing); ii) specialized supplier sectors (industries characterized by product innovations which are used by other sectors as capital goods where innovative activities are systematic but revolve mostly about design and tinkering, rather than fundamental research); iii) scale-intensive sectors (industries characterized by both process and product innovations with large-scale research activities); iv) science-based sectors (industries in which the search of innovations is tightly connected with exploration of the newly emerging technological paradigms and where, accordingly, innovative activities are linked to fundamental scientific research). In subsequent re-workings of the taxonomy, Pavitt introduced a fifth category namely, information-intensive sectors, in which innovation is related to developing capabilities in the processing and storage of complex data (Pavitt et al. 1989; Pavitt 1990).

The dichotomy between Schumpeter Mark I and II regime provides a somewhat starker characterization of innovation patterns, by revisiting the distinction between the early view of innovation that Schumpeter advanced in The Theory of Economic Development (Schumpeter 1911) ("Schumpeter Mark I") and the later view proposed by Schumpeter in Capitalism, Socialism and Democracy (Schumpeter 1942) ("Schumpeter Mark II"). Schumpeter Mark I industries are characterized by turbulent environments with relatively low entry barriers, where innovations are (mostly) generated and developed by new, or relatively young, 'entrepreneurial' firms. Accordingly, technological competition among firms in Schumpeter Mark I industries assumes the form of entrepreneurial "creative destruction", with successful innovating entrants replacing incumbents. In contrast, Schumpeter Mark II industries are characterized by stable environments 
with relatively high entry barriers in which innovations are generated and developed by large established firms. In Schumpeter Mark II industries, technological competition assumes the form of routinized "creative accumulation", with incumbent firms introducing innovations by means of a process of consolidation of their technological capabilities along well-established technological trajectories (Malerba 2005: 382).

The characterization of sectoral patterns of innovation using the Pavitt-taxonomy or the Schumpeter Mark I and II regime dichotomy has been essentially adopted as a descriptive static notion for interpreting the empirical evidence emerging in crosssectional settings. It is, however, possible to develop a more insightful "dynamic" interpretation of these two classifications. As noted by Archibugi (2001), the Pavitt's taxonomy can be easily connected with the literature on long waves of capitalist development. According to Archibugi, each long wave described by Freeman and his associates (Freeman and Louça 2001), may be linked to the emergence of a new type of firms: supplier dominated (I Kondratiev), specialized suppliers (II Kondratiev), science based (III Kondratiev), scale-intensive (IV Kondratiev), information intensive (V Kondratiev) whose patterns of innovative activities are described by a specific category of the Pavitt taxonomy. Relatedly, the Schumpeterian Mark I and II regime dichotomy can be interpreted within an industry-life cycle perspective, with the Schumpeter Mark I and II pattern characterizing the early and the mature stages of the evolution of industries respectively (Malerba 2005).

Both the Pavitt taxonomy and the Schumpeter Mark I and II regime dichotomy have proved extremely successful in capturing the sectoral specificity of innovation profiles in industries and they have been widely accepted, shared, and improved by scholars of innovation studies (Peneder 2010; Castellacci 2008; Marsili 2001; Evangelista 2000). Figure 1 provides a simple bibliometric assessment of the fortunes of the key-contributions of the literature on sectoral patterns of innovation.

More precisely, the figure reports the yearly number of citations in the Scopus dataset of: Pavitt (1984), Malerba and Orsenigo (1995, 1996, 1997), and Breschi et al. (2000). The series "Schump" is the sum of all the citations received by the papers using the Schumpeterian Mark I and II distinction, namely: Malerba and Orsenigo (1995, 1996, 1997) and Breschi et al. (2000). Interestingly enough, the two series Pavitt and "Schump" display a similar evolution as they experience a rather steady growth until the early 2010 s followed by what seems to be a phase of decline. Of course, it might be too early to reckon whether the recent drop in the number of citations in Fig. 1 reflects a diminishing impact of these contributions, which, for long time, had been acknowledged of major importance in the field of innovation studies. Nevertheless, the trend observed Fig. 1 is consistent with what seems to be the approach most in vogue today for dealing with inter-industry differences in patterns of innovation. In most exercises, the specificities of the sectoral context in which innovative activities take place are treated as confounding factors that simply need to be "cleaned" in order to arrive to a non-spurious estimation of the relationship under scrutiny, typically by means of specifications that contain a fixed effect at industry level. Note that, in most cases, the discussion of the fixed effect estimates specified at the level of industry and/or technology class is just given cursory notice. 


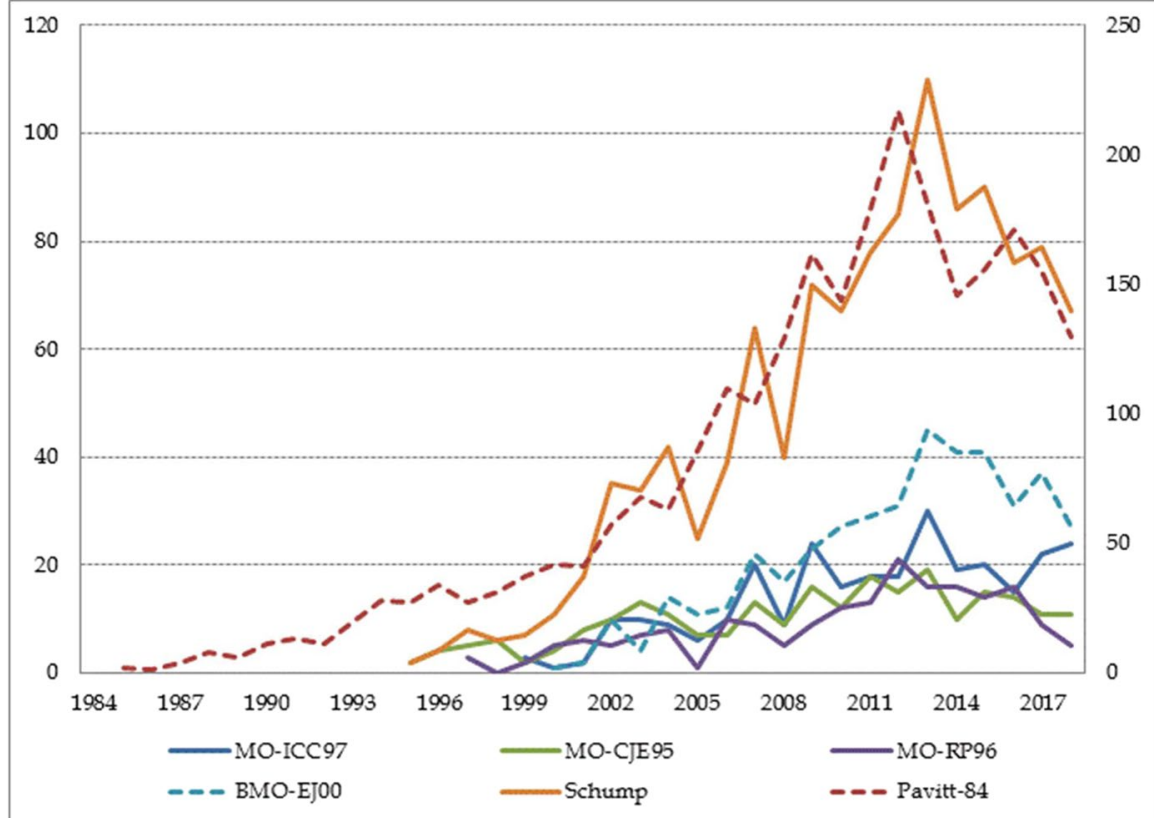

Fig. 1 A bibliometric assessment of key-contributions of the literature on sectoral patterns of innovation

In this paper we go back to the original formulation of the literature on sectoral patterns of innovation. More specifically, we revisit the empirical relevance of the Schumpeter Mark I and II regime dichotomy to check whether it remains a useful characterization of sectoral patterns of innovative activity. From the methodological viewpoint, our study should be intended as a "quasi-replication" of the exercise carried out in Breschi et al. (2000). "Quasi-replications" assess the generalizability of the results of prior studies to new contexts or the robustness of prior studies to different empirical approaches, methods, measures, and models (Bettis et al. 2016). Our analysis relies upon a more recent, expanded and greatly improved dataset of innovations in several industries and countries with respect to the original one. Our aim is to provide fresh support to the idea that Schumpeterian regimes matter and sectoral specificities in the pattern of innovative activities deserve a treatment which should go above and beyond the one they receive in most of the current empirical analyses. In this respect, our study is important in the light of the recent contributions (Srholec and Verspagen 2012) who have argued that firms' innovation strategies are actually characterized by a much stronger degree of intra-sectoral, rather than inter-sectoral heterogeneity. While a certain degree of intra-sectoral heterogeneity may exist, our results show that sectoral specificities still shape in a major way firms' inventive activity.

The paper is organized as follows. In the next section we discuss the previous studies devoted to measuring the different dimensions of technological regimes and their role in shaping Schumpeterian Patterns of Innovation (SPIs from now 
on). Section 3 describes our method and empirical strategy. Section 4 presents our findings. Section 5 concludes.

\section{Background literature}

Malerba and Orsenigo's reappraisal of the Schumpeter Mark I and II regime dichotomy has appeared in a series of papers published between 1995 and 2000 in which they provided a systematic examination of the sectoral patterns of innovation in a set of advanced capitalist countries using patent data. ${ }^{1}$ In general, they found that it was possible to use the notion of SPIs to characterize the variety in the sectoral profiles of innovative activities in all the countries of their sample. In particular, Malerba and Orsenigo (1995) examined patterns of innovation in different technology classes using USPTO patents over the period 1969-1986 for four European countries (Germany, France, UK and Italy), while Malerba and Orsenigo (1996) carried out a similar exercise using EPO patents over the period 1978-1991 for six major industrialized countries (USA, Germany, UK, France, Italy and Japan). The dimensions considered in the assessment of the patterns of innovation were: i) concentration and asymmetries among innovating firms in each sector (measured respectively, by the $\mathrm{C} 4$ concentration ratio and the Herfindahl index computed using the shares of patents hold by different firms); ii) size of the innovating firms (measured as the total share of patents in the technology class belonging to firms with more than 500 employees); iii) changes over time in the hierarchy of innovators (measured using the Spearman correlation coefficient of the patents owned between the innovating firms in different periods); iv) relevance of the entry of new innovators (measured as the share of patents of firms applying for the first time in a specific technology class).

Malerba and Orsenigo's findings suggested that technology classes with low concentration and reduced asymmetries among innovating firms were characterized by relatively small size of innovating firms, changes in the hierarchy of innovators and considerable innovators' entry, pointing towards a Schumpeter Mark I pattern. By contrast, technology classes with high concentration and asymmetries among innovating firms were characterized by relatively large size of innovators, a relative stability in the hierarchy of innovators, and limited entry, pointing towards a Schumpeter Mark II pattern. These results were further corroborated by a principal component analysis on the variables mentioned above. In all countries, the principal component analysis produced one dominant factor (explaining in all cases more than $50 \%$ of the variance) the loadings of which are fully consistent with the Schumpeter Mark I/Schumpeter Mark II distinction. The overall conclusion of these investigations was the recognition of systematic differences across industries in the patterns of innovation (differences that it is possible to characterize in terms of the Schumpeter Mark I and Schumpeter Mark II regime dichotomy) and of similarities across

\footnotetext{
${ }^{1}$ For a very insightful survey and discussion of the empirical literature on the Schumpeter Mark I and II dichotomy see Orsenigo (1995).
} 
countries in sectoral patterns of innovation for a specific technology (Malerba and Orsenigo 1997: 94).

Malerba and Orsenigo's interpretive hypothesis of these findings was that the emergence of these two sectoral patterns of innovation is accounted for by different 'technological regimes 'that shape and constrain innovative processes in different sectors. In their definition, a technological regime is a synthetic description of the technological environment in which firms act. More specifically, a technological regime is a specific combination of some basic characteristics of technologies: opportunity conditions, appropriability conditions, cumulativeness of technical progress, and the nature of the knowledge base (Malerba and Orsenigo 1997: 94). The hypothesis is that Schumpeter Mark I patterns of innovation emerge in contexts characterized by high technological opportunities, low appropriability and low cumulativeness, whereas Schumpeter Mark II pattern emerge in contexts of high appropriability and cumulativeness (technological opportunities can be either high or low). Breschi et al. (2000) provided a first (successful) test of these hypotheses concerning the relationship between technological regimes and sectoral patterns of innovation combining data from the PACE innovation survey with EPO patents to measure the relevant dimensions of the technological regimes and the sectoral patterns of innovation.

Further contributions have confirmed the merits of introducing the Schumpeter Mark I/ Schumpeter Mark II distinction. Van Dijk (2000) studied the industrial structure and dynamics in Dutch manufacturing and found consistent differences in the patterns of industrial dynamics between Schumpeter Mark I and Schumpeter Mark II industries. The distinction between Schumpeter Mark I and Schumpeter Mark II seems also useful to study patterns of innovation with broad technological fields. For example, Corrocher et al. (2007) have shown the existence of Schumpeter Mark I and Schumpeter Mark II patterns of innovation examining patents taken in different sub-segments of ICT applications.

Other works have explored the connection between technological regimes and indicators of innovation performance. Castellacci (2007) studied the relationship between differences in sectoral productivity growth and technological regimes in nine European countries (Germany, France, Italy, Netherlands, Norway, Portugal, Sweden, UK and Austria) in the period 1996-2001. Technological regimes are defined in terms of technological opportunities, appropriability and cumulativeness, and the measurement of the different dimensions of technological regimes is based on responses to the Community Innovation Surveys (CIS). He finds that Schumpeter Mark II sectors are characterized by higher rates of productivity growth. Therefore, the relationship between the different characteristics of the technological regimes and productivity is different in the two SPI. In a related study, Fontana et al. (2012) have investigated the connection between SPI and the generation of breakthrough innovations measured using the innovations winning the 'R\&D 100 Awards' competition organized by the magazine Research and Development. They find that 'turbulent' Schumpeter Mark I type of contexts are more likely to lead to breakthrough innovations than routinized regimes associated to Schumpeter Mark II contexts. Finally, Bodas Freitas et al. (2017) looked at whether the effect of R\&D tax credits vary across sectors. Combining three waves of the CIS carried out in Norway, Italy 
and France for 2004, 2006 and 2008, the study estimated input and output additionality effects of R\&D tax credits how these effects differ across sectors characterized by different $R \& D$ orientation and competition conditions. Their results indicate that firms in industries with high R\&D orientation (i.e., Schumpeter Mark II) have on average higher propensity to apply to R\&D fiscal incentives schemes and stronger input and output additionality effects. Whereas the extent of output additionality is lower for industries with low R\&D orientation (Schumpeter Mark I).

\section{Methods and materials}

Our analysis is a 'quasi-replication' of the work on SPI carried out by Breschi et al. (2000). A quasi-replication is here defined as a "[...] study that uses equivalent or better quality data than the original study and replicates the methods and variable construction of the original study as closely as possible" (Bettis et al. 2016: 260). In this respect it differs from 'internal replications' (Hamermesh 2007), which require to use the exact same sample and population of the original analysis. It is also different from 'statistical replication' (different sample but identical model and underlying population) or from 'design replication', which employs an alternative research design to answer the same questions of prior work (Muma 1993). For reasons that will be explained below, our empirical analysis will replicate the original research design but will employ additional control variables, alternative measures, and indicators. The main objective is not to 'prove' or 'disprove' the original results but to "alter the balance of evidence" (Bettis et al. 2016: 260) in the sense of: assessing the generalizability of the results to a new context; check their robustness to different empirical measures; provide a further contribution to the body of knowledge on technological regimes. ${ }^{2}$ In this section, we will present the data, the variables and the empirical model with a specific focus on the possible differences with the "original" paper.

\subsection{Data}

Our original dataset has been obtained from merging two data sources: the EPOPATSTAT Database (Version 2018) and the Community Innovation Survey (CIS). ${ }^{3}$ To avoid possible country-bias arising from the arbitrary selection of a specific national patent office, we employ all the DOCDB patent families with at least one patent granted either at the European Patent Office (EPO) or the United States

\footnotetext{
${ }^{2}$ Indeed, we share the consideration that: "[...] a single replication cannot overturn prior evidence any more than a single empirical study can establish that we 'know' something with certainty" (Bettis et al. 2016: 260).

3 We are aware that patents, as indicators of innovation, may have many shortcomings ranging from skewness of patenting activity towards big firms (Mansfield 1986), differences in the propensity to patent across industries (Fontana et al. 2013) and type of innovation (Arundel and Kabla 1998). These shortcomings notwithstanding, patents indicators are available across industries and over time. Moreover, they have been extensively used in prior empirical studies of technological regimes.
} 
Patent and Trademark Office (USPTO) with first filing between 1977 and 2015. ${ }^{4}$ To better capture changes over time in the relatively 'slow-changing' dynamics of our indicators of technological regimes, we chose not to analyze our data yearly, but we divided them into 12 windows of 3-years each. We refined this initial sample focusing on the assignees of eleven countries: Italy, Germany, UK, France, Switzerland, Sweden, The Netherlands, Japan, US, China, and South Korea. As the analysis is carried out at the industry level, we assign each family to a 2-digit NACE Rev. 2 class using the concordance table developed by van Looy et al. (2015). ${ }^{5}$ The final sample includes 4,153,570 patent families with 326,360 assignees distributed across 44 NACE Rev. 2 industries. ${ }^{6}$ Concerning the CIS data, we employed the results of seven waves (i.e., since CIS 3 related to the period 1998-2000) aggregated at country and industry level. ${ }^{7}$

The integration of such heterogeneous data sources presented some criticalities. First, the two sources have different time frequencies which create some issues when we tried to combine them to perform the econometric exercise (see Section 3.4 below). Second, while both sources directly used or could be translated into the NACE sector classification, some differences remained. In some cases, early waves of CIS results have been aggregated according to the NACE Rev. 1 classification and then converted into the Rev. 2. In other cases, not all the NACE Rev. 2 classes available from the EPO-PATSTAT Database have found correspondence in the aggregated CIS results. Thus, some limited manual cleaning was performed.

Table 1 below highlights the main differences between our data sample and the one employed by Breschi et al. (2000).

The following differences are noteworthy: i) our time frame for the analysis is longer than in the original study: 1977-2015 vs. 1978-1991; ii) the coverage of the patents used: EPO and USPTO in this study vs. only EPO patents in the original work; iii) the definition of industry which is now done using NACE classes vs. IPC classes; and iv) the number of countries included in the analysis: 11 vs. three in the original study. ${ }^{8}$ In addition to this, instead of using the CIS, Breschi et al. (2000) employed the PACE (Policy, Appropriability and Competitiveness for European Enterprises) a survey addressed to 713 R\&D executives from the European union's largest manufacturing firms with several questions about their innovative activities (Arundel et al. 1995). While the PACE survey provides direct answers on aspects

\footnotetext{
4 As European firms tend to patent more at the EPO rather than the USPTO, and similarly, U.S. firms tend to patent more at the USPTO rather than the EPO, any patent count based only one of these offices would introduce a bias in the analysis. To avoid this bias, we employ patent families which allow us to use all the national patents while avoiding double counting.

5 This concordance table is already "integrated" in the EPO Patstat Database where the table TLS229_ APPLN_NACE2 assigns each patent application to one or more NACE Rev. 2 codes. If a patent maps into more than one Rev. 2 class, we count the patent multiple times.

6 See Appendix for the list of NACE Rev. 2 codes.

7 These data have been accessed online at the EUROSTAT webpage: https://ec.europa.eu/eurostat/web/ microdata/community-innovation-survey. Table 6 in the Appendix reports the time alignment between 'patent based' variables and variables constructed from the CIS surveys.

8 Malerba and Orsenigo (1996) includes also France, Japan, and United States.
} 

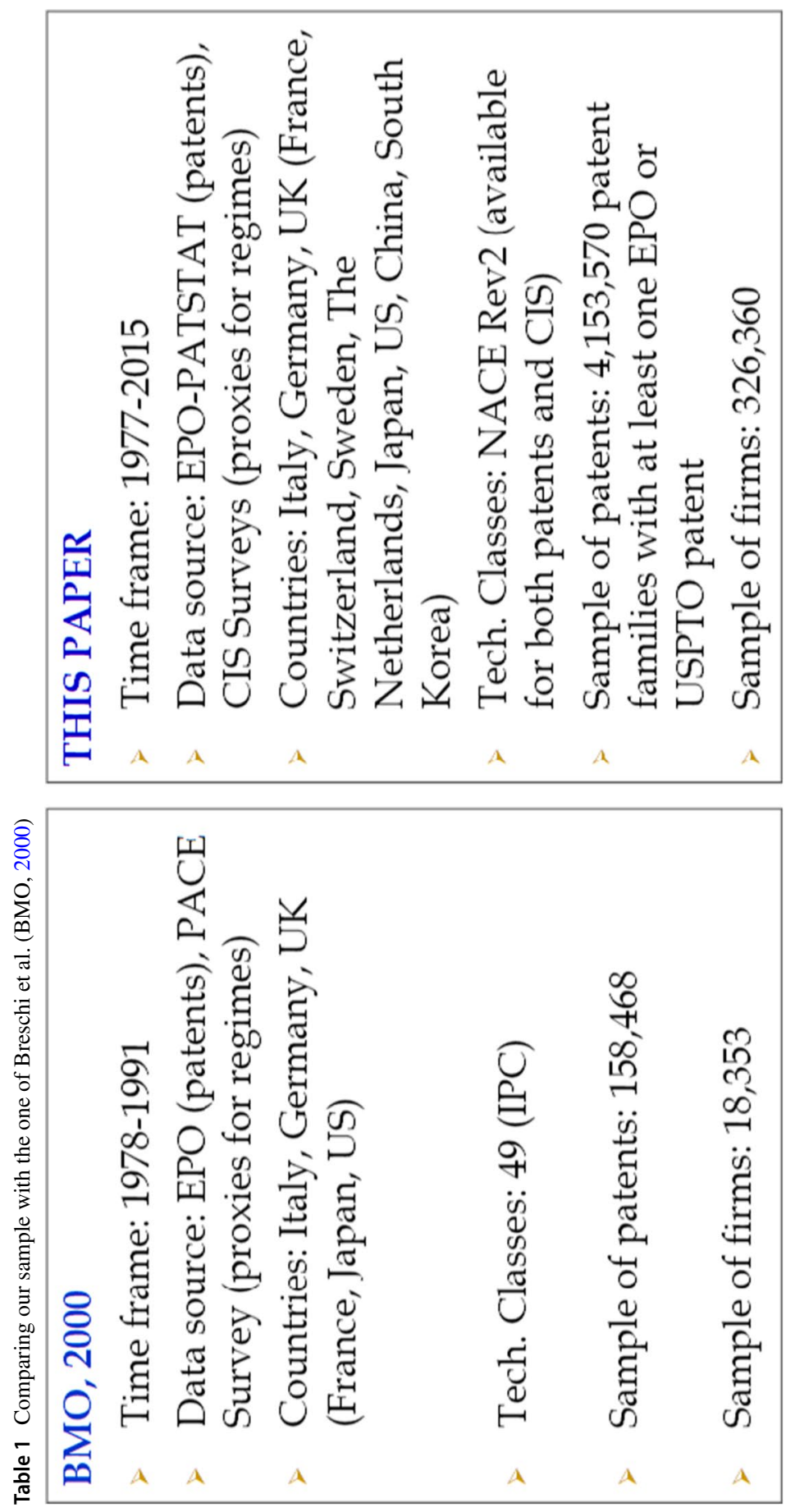
related to technological regimes, it focused on a few large European companies allowing only a partial cross-sectional snapshot for the 1990-1992 period. ${ }^{9}$

\subsection{Using patent data to identify Schumpeterian Patterns of Innovation (SPI)}

Analogously to what has been done in the prior literature (Malerba and Orsenigo 1995; Malerba and Orsenigo 1996; Malerba and Orsenigo 1997) our first step was to identify SPI using indicators of: entry, concentration, and stability, computed from patent data. While the starting dataset described in Section 3.1 includes more than four million patent families, we calculated the three indicators at the industry (i.e., 2 digit level of the NACE Rev. 2) and country level focusing on 11 3-years-windows between 1986 and 2015. ${ }^{10}$

ENTRY $_{\mathrm{I}, \mathrm{C}, \mathrm{P}}$ is computed as the share of patent families filed by new assignees over the total number of patent families in industry $i$, in period $p$, by assignees from country $c$. New patentees are identified using the PATSTAT Standardized Name and comparing the list of innovators in each period with the list of innovators in the previous one. ${ }^{11}$ We computed $\mathrm{C}_{\mathrm{I}, \mathrm{C}, \mathrm{P}}$ as the sum of the shares of patent families filed by the top four innovators in industry $i$, in period $p$, by assignees from country $c$. Also in this case, innovators are identified using the PATSTAT Standardized Name. Finally, the variable STABILITY $_{\mathrm{I}, \mathrm{C}, \mathrm{P}}$ is the Spearman correlation between the ranking of innovators from country $c$ in industry $i$, over the period $p$ and compared with the same ranking in the previous period. The Spearman correlation varies between -1 and 1 , moving from opposed to identical rankings.

\subsection{Using CIS to define indicators of technological regimes (TRs)}

The indicators to characterize TRs are: technological opportunity, technological appropriability, technological cumulativeness, and type of knowledge base. They were computed using both CIS and patent data. OPPORTUNITY ${ }_{I, C, P}$ was defined as the sum of the number of firms that in the CIS declared highly important six external information sources (i.e. suppliers, users, university or public research center, affiliated firms, and competitors) in industry $i$, over the period $p$ by firms from country c. ApPROPRIABILITY ${ }_{\mathrm{I}, \mathrm{C}, \mathrm{P}}$ was computed as the share of firms that in the CIS declared to have introduced innovations new to the market over the total number of firms that introduced innovations new to the firm in industry $i$, over the period $p$ by firms from country $c$. The logic underlying this indicator is that innovations new to the market are more valuable and they are more likely to be well protected by the firm,

\footnotetext{
9 See note 15 in Breschi et al. (2000) for a list of recognized criticalities of the PACE survey.

10 Note that the patents prior to 1986 are used as a "baseline" to calculate the ENTRY and STABILITY indicators for the first period then included in the analysis.

11 The EPO-PATSTAT Database provides in Table 206 a standardized name (the variable PSN_NAME) and a unique id (the variable $P S N_{-} I D$ ). These variables result from the University of Leuven harmonization procedure. See the EPO-PATSTAT documentation available at: http://documents.epo.org/proje cts/babylon/eponot.nsf/0/11CE75EDDF734288C125848F0048F533/\$FILE/data_catalog_global_v5.14_ autumn_2019_en.pdf
} 
as compared to innovations that are already known in the market and perhaps imitated in the past. ${ }^{12}$ The last two indicators were computed using the patents data already used for the analysis of the SPIs. These are the ones that differ the most from the original work by Breschi et al. (2000). ${ }^{13}$ CuMULATIVENESS $_{I, C, P}$ is calculated as the average of the normalized number of backward citations made by all the patents related to industry $i$, over the period $p$ by assignees from country $c$. Finally, KNowLEDGE BASE $_{I, C, P}$ uses the average of the normalized non patent literature citations made by all the patents related to industry $i$, over the period $p$ by assignees from country $c$. For the sake of comparability these indicators have been normalized by subtracting the min of the value and dividing the result by the difference between the max and the min computed upon the pooled sample.

\section{The SCHUMP variable and the econometric analysis}

To provide a synthetic indicator of the SPI, we performed a principal component analysis using EnTRY, C4, and StABility. The final dataset includes 5136 observations distributed over 11 periods, 11 countries, and 44 industries.

This analysis performed on the pooled data indicates the presence of one factor that explains the $49 \%$ of the total variance. ${ }^{14}$ This factor loads positively on STABILITY and C4 and negatively on ENTRY, which is consistent with the original findings of Breschi et al. (2000). We then generated the variable ScHUMP, computed as the factor score coefficients resulting from the principal component analysis. In particular, a positive and higher value of SCHUMP indicates structural features of a Schumpeter Mark II industry. Conversely, a negative and lower value of ScHUMP indicates structural features of a Schumpeter Mark I industry.

Finally, to analyze the association between SPIs and TRs we estimated the following regression:

$$
\begin{aligned}
& \text { SCHUMP }_{I, C, P}=\alpha+\beta_{1} \text { APPROPRIABILITY } Y_{I, C, P_{-} C I S}+\beta_{2} \text { OPPORTUNITY }_{I, C, P_{-} C I S}+
\end{aligned}
$$

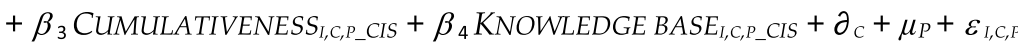

CIS are generally administered every two years and refer to innovation activities carried out in the previous three years. As we expect that it might take some time for the characteristics of TRs to eventually affect the SPI we lagged each regressor by one period. The Appendix Tables 4, 5 and 6 reports how we aligned the periods of the SPI and TR variables and, therefore, how we defined the period P_CIS. Finally, CIS data are available only for European countries, and the two questions needed for computing OPPORTUNITY and APPROPRIABILITY are not included in all the waves for all the European Countries. Therefore, the econometric exercise is performed only on three countries (Italy, Germany and the UK) over a relatively restricted time frame.

\footnotetext{
${ }^{12}$ We thank Francesco Lissoni for useful discussions on how to operationalize the appropriability dimension.

${ }^{13}$ See the Appendix for a comparison between the variables used in this paper and in the Breschi et al. (2000).

${ }^{14}$ See the Appendix for detailed results of the principal components analysis.
} 

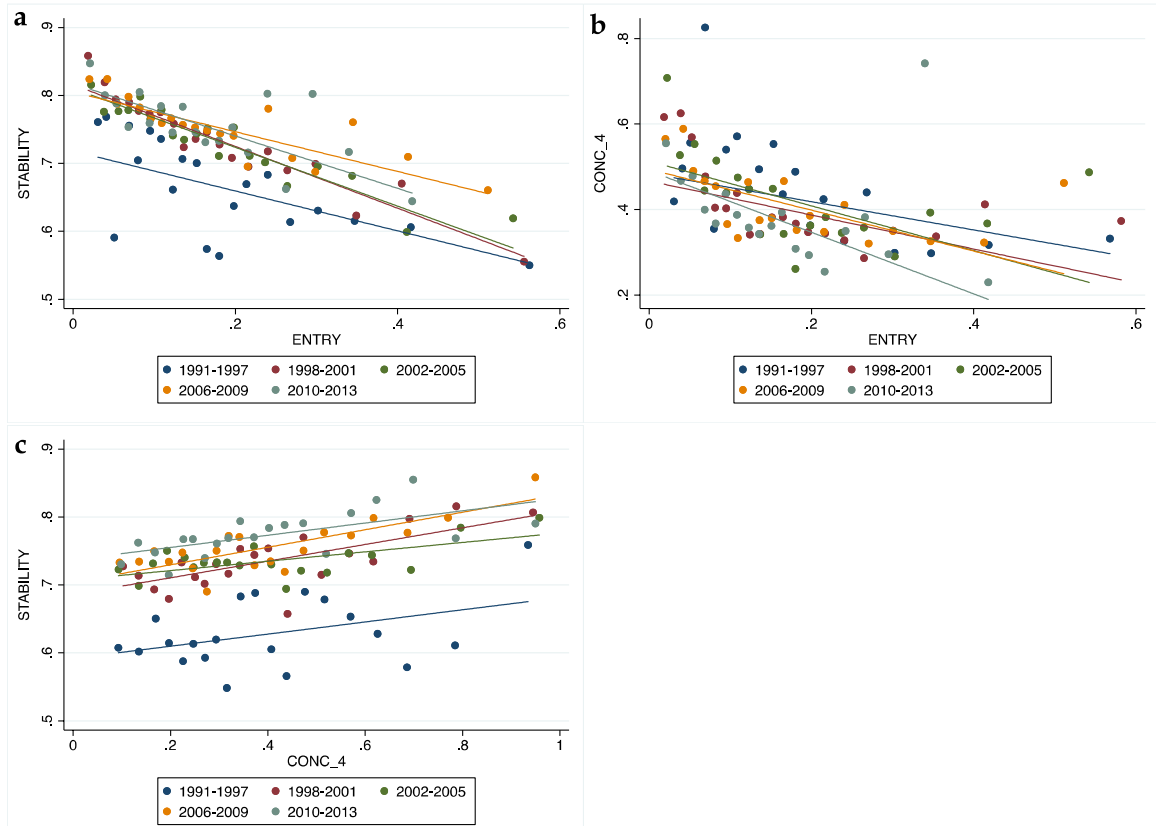

Fig. 2 a, b, c Identifying Regimes. Note: We use binned scatterplots with 20 equal-sized bins for the variable on the $\mathrm{x}$-axis. Each dot does not represent an individual observation but the mean of the $\mathrm{x}$-axis and $y$-axis variables within each bin. The line represents the linear fit of the data by period

\section{Descriptive statistics}

\subsection{Identifying regimes}

We start our analysis by providing some descriptive statistics on SPI. In particular, we plot the relationship between Entry, Concentration, and Stability, the characteristics that define a SPI (Figs. 2a-c).

Table 2 Cross country similarities (factor loadings of Principal Component Analysis)

\begin{tabular}{llll}
\hline Country & STABILITY & ENTRY & C4 \\
\hline Switzerland & 0.6899 & -0.7058 & 0.1606 \\
China & 0.717 & -0.6727 & 0.1824 \\
Germany & 0.6381 & -0.6972 & 0.3268 \\
France & 0.6638 & -0.6729 & 0.3265 \\
United Kingdom & 0.6344 & -0.6858 & 0.3567 \\
Italy & 0.628 & -0.6304 & 0.4563 \\
Japan & -0.6721 & 0.6916 & 0.2645 \\
Korea & -0.695 & 0.6674 & 0.2675 \\
The Netherlands & 0.5008 & -0.6657 & 0.5532 \\
Sweden & 0.5619 & -0.6114 & 0.5572 \\
United States & 0.6746 & -0.6782 & 0.2914 \\
\hline
\end{tabular}


Fig. 3 a SPIs over time. European countries. b SPIs over time. Non-European countries

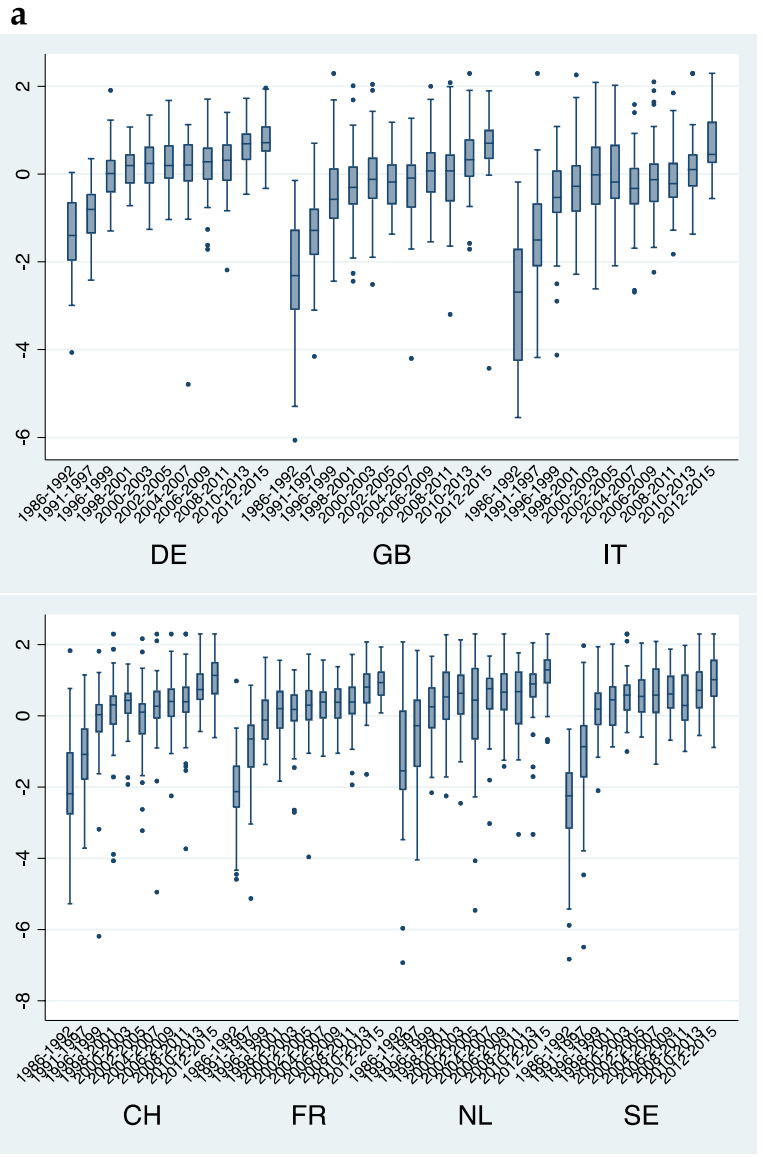

In the figures, each point corresponds to the mean of the $\mathrm{x}$-axis and $\mathrm{y}$-axis variables within 20 equal-sized bins of the $\mathrm{x}$-axis variables. ${ }^{15}$ Different shades are used to identify different time periods. While we can observe a negative correlation between entry and stability (Fig. 2a) and between entry and concentration (Fig. 2b), a positive relationship is observed between stability and concentration (Fig. 2c). These figures broadly support prior findings (Malerba and Orsenigo 1995, 1996; Breschi et al. 2000). Furthermore, we find also consistency in the temporal evolution of these relationships and we highlight a common pattern where the cloud of points that identifies a combination of sector and country moves from being more scattered in the early years to more concentrated in the later ones as to indicate convergence in the clustering of sectors/ country pairs. We further explore these results by investigating the extent in which the dimensions that define a SPI are relatively country

\footnotetext{
${ }^{15}$ Binned scatterplots are useful when plotting every data point would become too crowded to interpret visually. We draw the figures using the command 'binscatter' in STATA. The line represents the linear fitting of the data.
} 
Fig. 3 (continued)

b
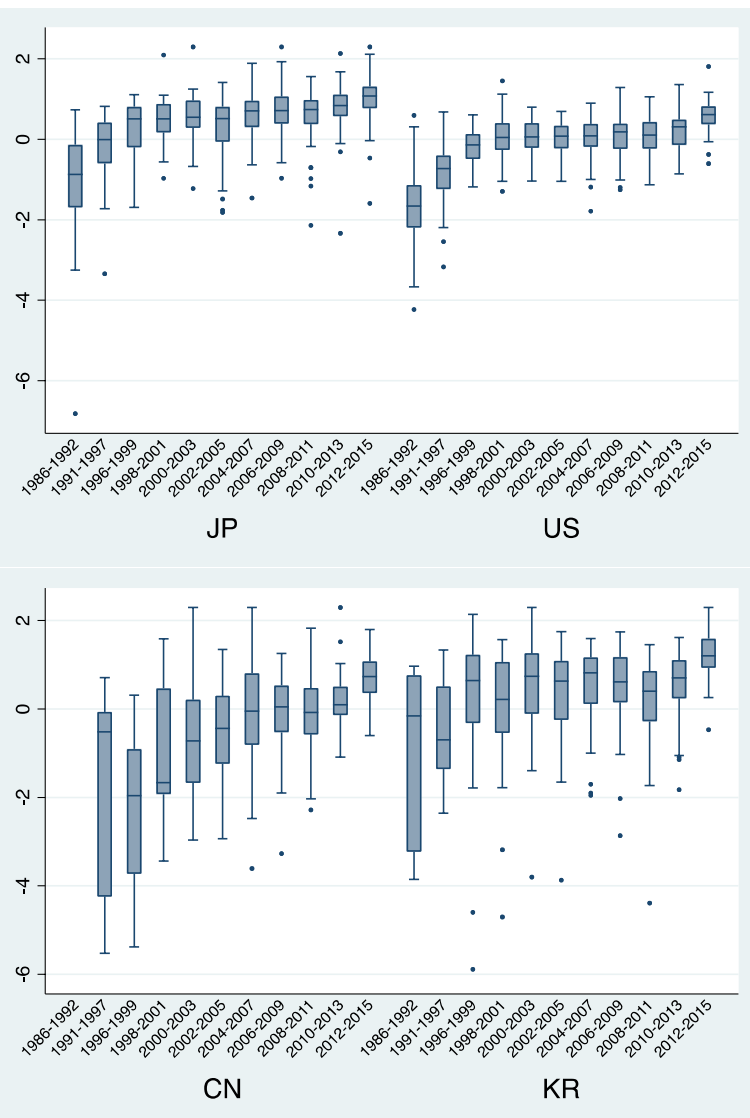

invariant. This aspect is one of the major findings of the literature on SPI. Table 2 reports the result of a Principal Component Analysis (PCA) by country.

Our results confirm the existence of a widespread similarity of SPI across countries, with the noticeable exceptions of Japan. This country displays a very peculiar industrial structure characterized by the presence of very large multi-product conglomerates (i.e., the Japanese keiretsu) that makes Schumpeter Mark II types of industries more present.

\subsection{Further results}

So far, our analysis has highlighted the relative cross-country invariance of the dimensions that define a SPI and hinted at an apparently convergence in the sector/ country pairs over time. To probe further into the latter result, we have investigated the temporal evolution of SPI at a country level by relying upon the variable ScHuMP 
Fig. 4 a Sector specificity of SPI (Germany). Note: The underlined sectors are the eight sectors driving the "deepening" pattern in the three countries analyzed. b Sector specificity of SPI (Italy). Note: The underlined sectors are the eight sectors driving the "deepening" pattern in the three countries analyzed. c Sector specificity of SPI (GB). Note: The underlined sectors are the eight sectors driving the "deepening" pattern in the three countries analyzed
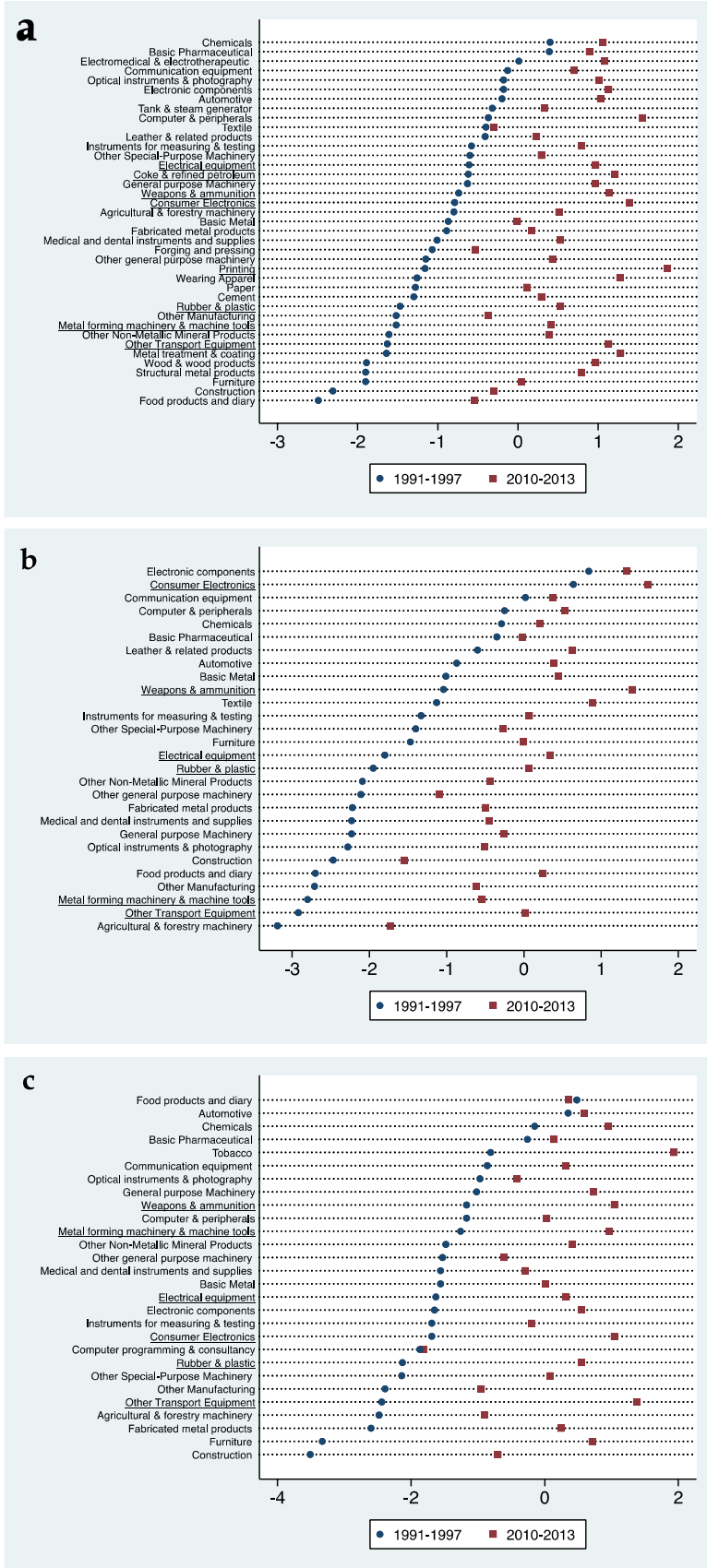

(see Section 3.4 above). In particular, we have computed the average values of the variable by country and plot the evolution over (three years window of) time. 
Figure 3a reports the results for European countries. In the upper panel of Fig. 3a, there are the three countries (i.e., Germany (DE), UK (GB) and Italy (IT)) included in the Breschi et al. (2000) sample. In the lower panel, there are the additional European countries included in our sample but not in the original one (i.e., Switzerland $(\mathrm{CH})$, The Netherlands (NL), France (FR), and Sweden (SE)). Figure $3 b$ instead shows the results for the non-European countries included in our sample. It is striking that almost in all cases, the average value of Schump is negative at the beginning of the observation period but then increases over time therefore suggesting a transition from a 'widening pattern' of innovation associated to a Schumpeter Mark I regime to a 'deepening pattern' of innovation' typical of a Schumpeter Mark II regime for the countries and sectors included in our sample. The transition occurs at different 'speed' though, also depending on the initial value. It is the fastest for Germany, Switzerland, The Netherlands, and Sweden; relatively slower for UK, France; and the slowest for Italy. Among non-European countries, it is the fastest for Japan (JP); relatively slower for US and South Korea (KR); and the slowest for China (CN).

Taken together, the findings of Table 2 and Figs. 3a, b suggest that SPIs are relatively country invariant but not time invariant. Moreover, the dynamics presents similarities across countries. To unravel the general trends of the 'deepening' dynamics just highlighted, we zoom into the SPIs time dynamics of the three countries included in the Breschi et al. (2000) sample. Figure 4a-c shows the change of the variable Schump between the earliest period (1991-1997) and the most recent period (2010-2013) by sectors.

While these figures suggest that deepening occurs in almost every sector, some differences emerge. In fact, sectors 'deepen' to a different extent as shown by the heterogeneity in the distance between the two markers in the figures, indicating that, within countries, sector ranking changed over time. Interestingly, the same sectors seem to drive the changes. Consistency is observed in 8 sectors that 'gain positions' in each EU country: Consumer electronics and Electrical equipment (Science based according to the Pavitt taxonomy); Coke \& refined petroleum, Rubber \& Plastics, Printing, Other transportation (Scale intensive); Metal forming machinery \& machine tools, Weapon and ammunition (Specialized suppliers). Other 4 sectors remain 'stable' or 'decline': Basic pharmaceuticals (Science based); Chemical (scale intensive); Other generalpurpose machinery, Optical instruments \& photography (Specialized suppliers).

\section{Econometric exercise}

The descriptive analysis carried out in the previous sections has highlighted that SPI tend to be industry-specific and that they can be aptly captured across countries in term of 'entry', 'concentration' and 'stability'. These findings corroborate some of the existing results in the literature on SPI. In addition to this, our evidence has also highlighted that SPI change over time in a similar fashion in the sense that they tend to become Schumpeter Mark II. While this finding is consistent with the industry life-cycle literature, it is new in the sense that it was not directly discussed by prior empirical works on SPI. Finally, our findings also pointed to specific sectors that seem to drive the 'deepening' of the SPI. 
Table 3 The effect of Technological Regimes on SPIs. Dependent variable: SCHUMP

\begin{tabular}{|c|c|c|c|c|c|c|c|}
\hline & \multirow[b]{2}{*}{ (1) } & \multirow[b]{2}{*}{ (2) } & \multirow[b]{2}{*}{ (3) } & \multirow[b]{2}{*}{ (4) } & \multicolumn{2}{|l|}{ WEAK HP } & \multirow{2}{*}{$\begin{array}{l}\text { STRONG HP } \\
\text { (7) }\end{array}$} \\
\hline & & & & & (5) & (6) & \\
\hline \multirow[t]{2}{*}{ APPROPRIABILITY } & 5.0344 & & & & 8.0922 & 7.6594 & 4.1791 \\
\hline & {$[1.0872]^{* * *}$} & & & & {$[1.1319]^{* * *}$} & {$[1.1257]^{* * *}$} & {$[2.1094]^{*}$} \\
\hline \multirow[t]{2}{*}{ OPPORTUNITY } & & 2.3018 & & & 2.4288 & 1.9620 & 1.6275 \\
\hline & & {$[0.3791]^{* * *}$} & & & {$[0.3671]^{* * *}$} & {$[0.5164] * * *$} & {$[0.5251]^{* *}$} \\
\hline \multirow[t]{2}{*}{ Cumulativeness } & & & 0.0008 & & 0.004 & -0.0098 & -0.0075 \\
\hline & & & {$[0.0057]$} & & {$[0.0063]$} & [0.0069] & $0.0072]$ \\
\hline \multirow[t]{2}{*}{ KNOWLEDGE BASE } & & & & 0.0119 & 0.0099 & 0.0116 & 0.011 \\
\hline & & & & {$[0.0054]^{*}$} & {$[0.007]$} & {$[0.0071]$} & {$[0.0074]$} \\
\hline \multirow[t]{2}{*}{ Constant } & 0.2506 & -0.0701 & 0.3880 & 0.3679 & -0.3869 & -0.2117 & -0.2223 \\
\hline & {$[0.0408]^{* * *}$} & [0.0937] & {$[0.0847]^{* * *}$} & {$[0.0318]^{* * *}$} & {$[0.1205]^{* *}$} & [0.1978] & {$[0.2130]$} \\
\hline Country dummy & NO & NO & NO & NO & NO & YES & YES \\
\hline Period dummy & NO & NO & NO & NO & NO & NO & YES \\
\hline \#Obs. & 1129 & 908 & 1129 & 1129 & 908 & 908 & 908 \\
\hline Rsq. & 0.0206 & 0.0388 & 0.000 & 0.0027 & 0.0933 & 0.1349 & 0.1717 \\
\hline F-stat & 21.4412 & 36.8622 & 0.0205 & 4.8384 & 24.2787 & 17.8232 & 16.3571 \\
\hline
\end{tabular}

Heteroskedasticity-robust SE between brackets;

$* p<.05 ; * * p<.01 ; * * * p<.001$

Given these results, which seem to confirm the usefulness of our 'quasi-replication' exercise, the final step is to test whether the relationship between SPI and the characteristics of TRs holds, and it is robust to country and time fixed effects.

Table 3 reports the estimates for eq. (1) presented in Section 3.4. We estimate seven specifications in which the four indicators of TR are first introduced in sequence (Models 1 to 4), two specifications in which we consider them all together without and with country fixed effects (Model 5 and 6 respectively) and a final specification (Model 7) in which we add the time fixed effect. In each regression the dependent variable is Schump, computed as the factor score coefficients resulting from the principal component analysis (see Section 3.4 above). Model (5) tests the sectoral specificity of the relationship between the characteristics of the TRs (as captured by our proxies) and the SPIs. Model (6) test whether results of Model (5) are robust to country specificities (a sort of 'weak hypothesis'). Finally, Model (7) tests whether the results are also robust to time fixed effects (a sort of "strong hypothesis'). In Model (1) we observe that a higher level of APPROPRIABILITY is associated with a higher level of the variable SCHUMP and therefore to a Schumpeter Mark II (i.e., routinized) pattern of innovation. This finding is in line with the result in Breschi et al. (2000) and suggests that the ability to protect innovations from imitation increases the likelihood to observe a 'deepening 'pattern of innovative activities. Model (2) shows that also the coefficient estimate of OpPORTUNITY is positive and significant. This result indicates that a higher reliance upon external sources of knowledge for innovation is also positively associated with a 'deepening' pattern of innovation. This evidence contrasts with Breschi et al. (2000) who find instead a negative coefficient for this variable. We can speculate on the reasons why we observe this difference. Why it might be partly explained by differences in the 
measurement, it might as well be due to changes in the relevance of sectors that have been driving the pattern of deepening. 'Specialized suppliers', 'science based' sectors, but to a certain extent also the 'Coke \& refined petroleum' and 'Rubber \& Plastics', the two scale-intensive industries that have experienced a deepening pattern according to our previous analysis, rely relatively more than other sectors on external sources of information (i.e., customers, suppliers, universities and PROs etc.). Their observed dynamics might therefore explain the relationship we observe. ${ }^{16}$

In Model (3) we report the results for the variable CumulativenEss. The estimated coefficient is positive and in line with the previous literature on SPI. However, it is not statistically significant. In Model (4) the estimated coefficient for the variable KNOWLEDGE BASE is positive and significant, albeit weakly. This result indicates that a knowledge base characterized by external sources of knowledge (science) tend to be weakly associated to a 'deepening'(i.e., Schumpeter Mark II) pattern of innovative activities. A possible interpretation of this result is that in some Schumpeter Mark I contexts, the exploitation of scientific knowledge by small and dynamic firms (e.g., spinoffs and start-ups) is becoming increasingly important, and therefore this variable is no longer a strong discriminant of the two Schumpeterian patterns. This finding also resonates with the one of Breschi et al. (2000). The last three columns report the results for the full models with different types of fixed effects. Even with more restrictive specifications that control for country and time-invariant and factors, the previous results broadly hold.

All in all, these results from the econometric exercise confirm a trend towards increasing deepening of the pattern of innovative activity which had emerged from the descriptive analysis carried out in the previous section. With the exception of the sign of the coefficient estimate of 'opportunity' and 'cumulativeness', which is nevertheless measured very differently from the original study, they are also in line with the prior findings on SPI put forward by Breschi et al. (2000). In addition to this, the robustness of the findings to the introduction of time fixed effect, which is an extension with respect to Breschi et al. (2000), is also encouraging and suggests and confirm the utility of our 'quasi-replication' exercise. ${ }^{17}$

\footnotetext{
$\overline{{ }^{16}}$ To investigate this possibility, we rerun the estimation without the two scale intensive sectors 'Coke \& refined petroleum' and 'Rubber \& Plastics'. Results are unchanged. All in all, these results seem to suggest that, as in Breschi et al. (2000), the relationship between OPPORTUNITY and the Schumpeterian variables is not so straightforward. Indeed, it might be argued that the successful exploitation of technological opportunities depends upon how R\&D activities are organized. Sectors whose innovators rely more on external sources are characterized by more stability in the ranking of innovators, more concentration and less entry, all characteristics that are associated to a Schumpeterian Mark II pattern. This might indicate that external sources can be better exploited by firms that rely upon formalized and routinised $R \& D$ activities.

${ }^{17}$ It might be argued that our empirical exercise is conducted on a sample of patenting firms and industries which is rather different from the one used by Breschi et al. (2000), Indeed, our dataset includes one service sector (Computer Programming, Consultancy and Related Activities), while Breschi et al. limited their analyses mainly to the manufacturing industries on the ground that manufacturing had a greater economic weight than it does today. To understand whether the inclusion of the 'service sector' has any consequence for our results we have repeated the econometric exercise by excluding from the sample the patents taken in the service sector 'Computer programming consultancy and related activities'. Results, available upon request from the authors, are unchanged.
} 


\section{Conclusion}

Our empirical reappraisal of the empirical evidence concerning sectoral patterns of innovation and, in particular, our ‘quasi-replication' of the Breschi et al. (2000) empirical exercise suggests that the characterization of industries in terms of Schumpeter Mark I and II profiles and the related notion of technological regimes shaping innovative activities at sectoral level has been standing the test of time quite well.

In particular, we found that sectors may be consistently classified as Schumpeter Mark I or Mark II across countries. This result provides a significant corroboration of the interpretive conjecture entertained by Malerba and Orsenigo that "Schumpeterian patterns of innovation are technology specific". A qualification is in order, however. We have found a different configuration of the relationship between ENTRY, STABILITY and CONCENTRATION for Japan and South Korea. This is an interesting point which is in line with the notion that the observed patterns of innovative activities at sectoral level are actually the outcome of the interplay by the technological imperatives of the technological regime and the set-up of the national innovation system of the country in question (Orsenigo 1995).

Our findings point also to an interesting 'deepening' of SPI in a Schumpeter Mark II direction and we can speculate on what actually has been driving this pattern. In a life-cycle perspective, this finding can be accounted for by a number of sectors moving from a Mark I to a Mark II phase. In other words, the 'deepening' would reflect the maturation of a number of technological paradigms in a relatively wide spectrum of sectors. The emergence of new technological paradigms would instead shift again the pendulum in a Schumpeter Mark I direction. An alternative interpretation would be that we are currently witnessing, the structural shift from "entrepreneurial" to "trustified capitalism" envisaged by Schumpeter in 1942. According to this interpretation, in the future, we should expect innovative entry and turbulence to be a characteristic of the 'fringe' of sectors, while the 'core' would be increasingly dominated by the activity of a stable number of large-established firms. In a somewhat broader perspective, this interpretation of the intensification of 'deepening' pattern points to the co-evolution of market structure and technical change, in particular to the existence of strong feedback effect from market structure to the sources of technical change, as discussed in evolutionary models of Schumpeterian competition. ${ }^{18}$

It should be noted that our study suffers from a number of limitations. In particular, in order to construct a comprehensive dataset which would cover a wide range of countries for a prolonged time span, we have to adopt a cruder construction of the indicators characterizing the relevant dimensions of the technological regime. Our measurement of appropriability retrieved from the CIS questionnaire is probably a much more imperfect indicator than the PACE survey data, which offered a rather direct measurement of appropriability. Similarly, our assessment of the knowledge base is based only on citations and as such is not able to capture adequately the

\footnotetext{
18 " [...] whereas most analyses of the connection between market structure and innovation have viewed the causation as flowing from the former to the latter, under Schumpeterian competition, there is a reverse flow as well [...] Market structure should be viewed as endogenous to an analysis of Schumpeterian competition, with the connections between innovation and market structure going both ways" (Nelson and Winter 1982: 281).
} 
dimension of tacit knowledge which at conceptual level play an important role in the definition of technological regimes.

Despite these shortcomings, we think that our exercise has shown that the systematic empirical study of sectoral patterns of innovation can still yield important insights and potential for future research for scholars of innovation studies. There are two directions in which this research agenda might be expanded. First, it is crucial to connect the empirical research on innovation patterns with the data concerning the economic dimension of industrial dynamics (i.e., firms' survival and growth, profitability, productivity, etc.). For example, the global shift towards a Schumpeter Mark II pattern we have highlighted resonates well with recent empirical assessment of the productivity dynamics carried out by Andrews et al. (2016) who find a growing divergence, in many sectors, between the firms on the frontier and laggard firms. An interesting perspective for further research is to develop a connection between the study of patterns of inventive activities as developed in this paper and reconstruction of the evolution of productivity at sectoral level.

Second, it is important to establish a connection between the interpretation of sectoral patterns of innovation and the literature studying the development of technological capabilities at the firm level. So far this broadening of the compass of research on sectoral patterns of innovation in the direction of providing a comprehensive picture of patterns of industrial evolution rooted in specific technological regimes has been carried out at both the appreciative and the theoretical level in the form of 'history friendly models' of industrial evolution (Malerba et al. 2016).

In this respect, the main task ahead seems to improve the connection between sectoral patterns of innovation and the processes of learning at the technological and firm level, on the one hand, with the overall economic dimensions of industrial dynamics, besides inventive activities, also in terms of quantitative empirical research, on the other hand. This is precisely the direction of research that Gigi Orsenigo was pointing about 25 years ago:

“[...] the explanation of industrial dynamics can be found in links between taxonomies on 'species', on mutation processes, and on selection criteria. We have still rather incomplete and rough evidence on all three set of phenomena. And the theory joining them has yet to undergo stringent test for robustness. But significant progress has been made over the last decade or two: more systematic evidence has been collected, the growing field of economics of innovation has provided rich insights on micro learning processes; business economics has focused on the nature of problem-solving activities of firms and their related competences; and theoretical exercises on the properties of evolutionary processes are (slowly) spreading (Orsenigo 1995: 62-63)".

Progress has been made since then, but clearly most of the task is still unfulfilled. 


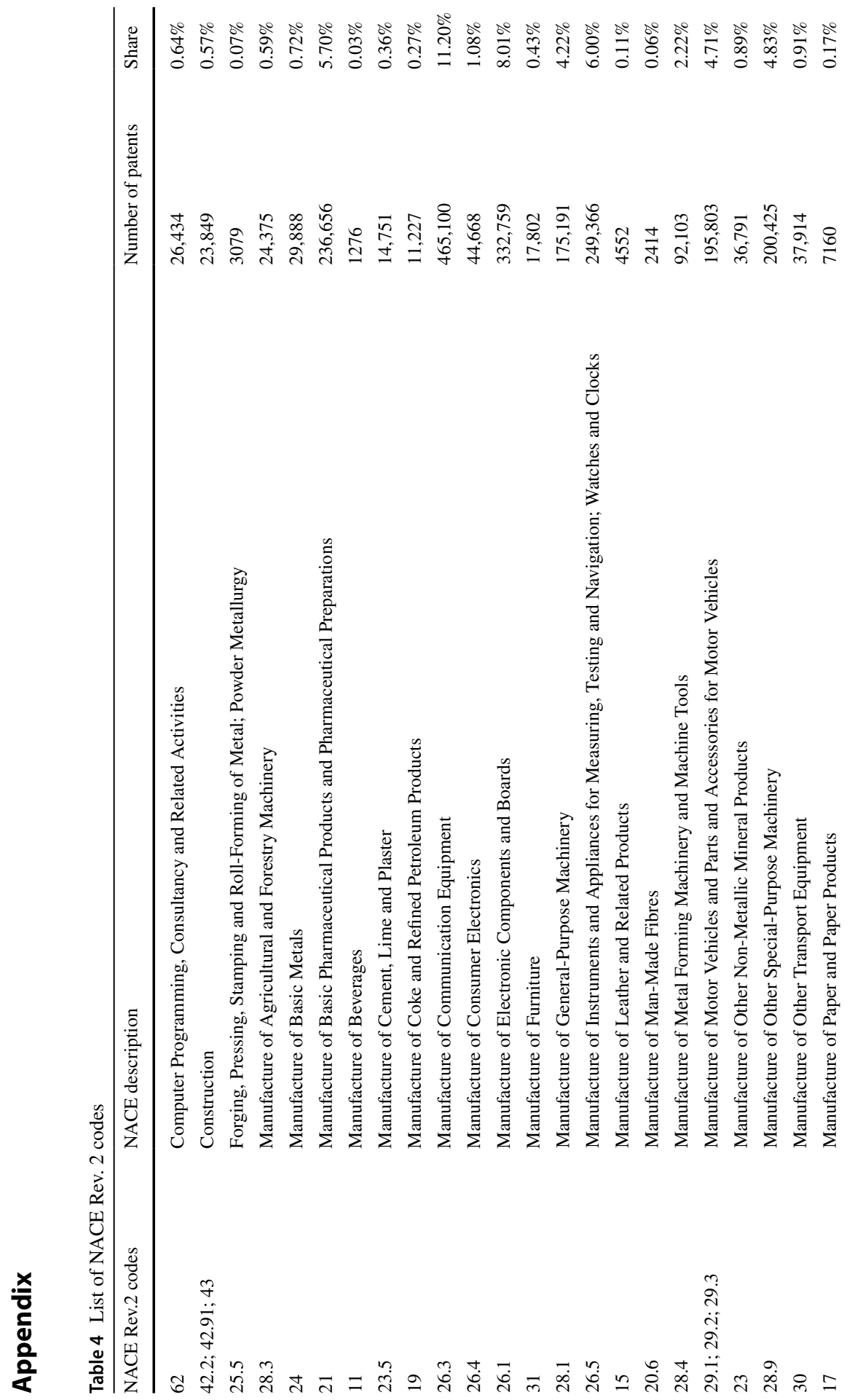




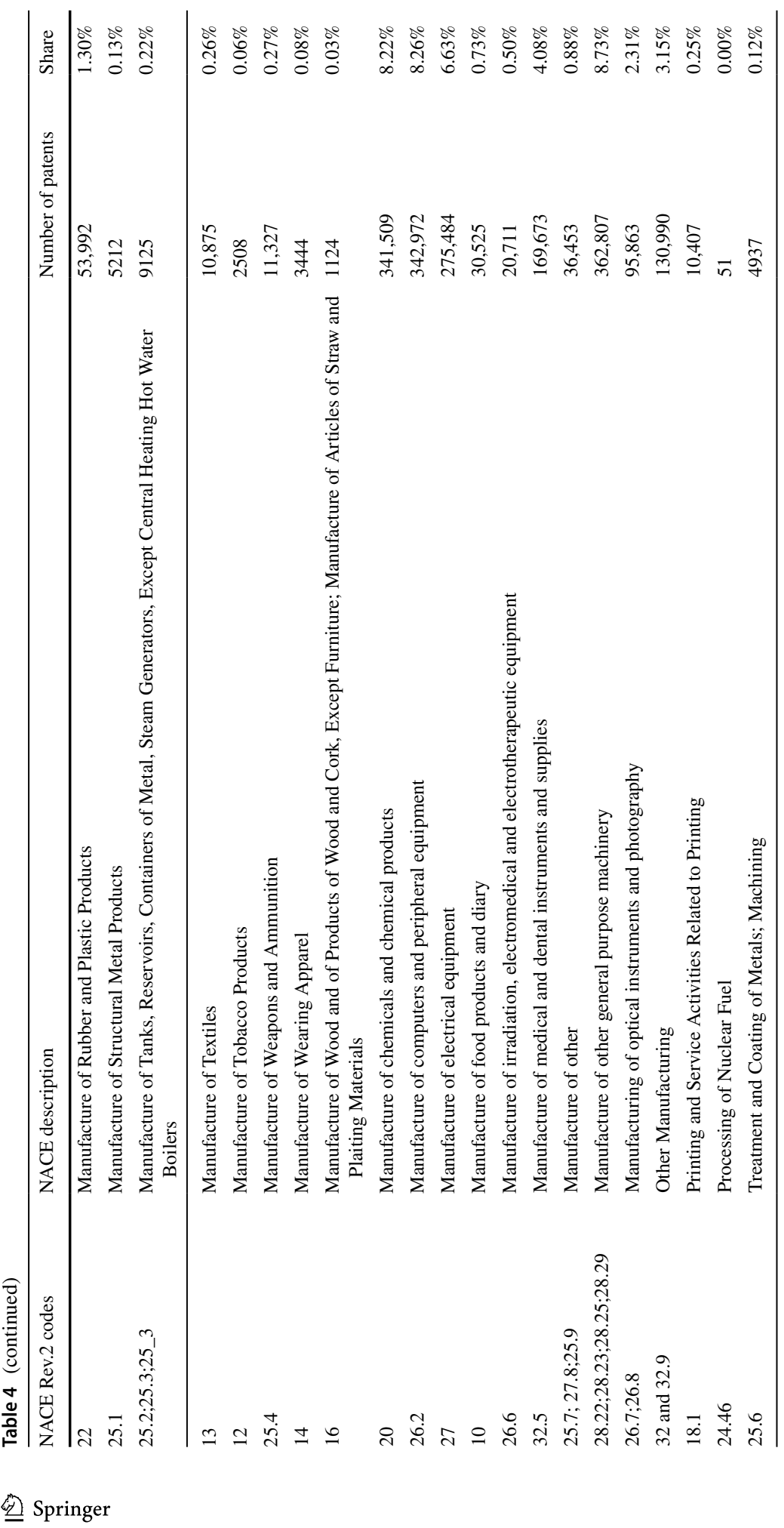


Table 5 A comparison of the variables used in this paper and in BMO (2000)

\begin{tabular}{|c|c|c|c|c|}
\hline \multirow[t]{2}{*}{ PERIOD } & \multicolumn{2}{|c|}{ PATENT DATA PERIODIZATION } & \multicolumn{2}{|c|}{ CIS DATA } \\
\hline & & & CIS & REFERENCE PERIOD \\
\hline 1 & 1977-1985 & & & \\
\hline 2 & 1986-1992 & & & \\
\hline 3 & $1991-1997$ & & & \\
\hline 4 & 1996-1999 & & & \\
\hline 5 & $1998-2001$ & & & \\
\hline 6 & $2000-2003$ & & & \\
\hline 7 & 2002-2005 & & & \\
\hline 8 & 2004-2007 & 2004-2007 & CIS4 & 2002-2004 \\
\hline 9 & 2006-2009 & 2006-2009 & CIS 2006 & 2004-2006 \\
\hline 10 & $2008-2011$ & $2008-2011$ & CIS 2008 & $2006-2008$ \\
\hline 11 & $2010-2013$ & 2010-2013 & CIS 2010 & 2008-2010 \\
\hline 12 & 2012-2015 & 2012-2015 & CIS 2012 & 2010-2012 \\
\hline
\end{tabular}

Table 6 Time alignment between patent-based variables and CIS-based variables

\begin{tabular}{|c|c|c|c|c|}
\hline \multirow[t]{2}{*}{ PERIOD } & \multicolumn{2}{|c|}{ PATENT DATA PERIODIZATION } & \multicolumn{2}{|l|}{ CIS DATA } \\
\hline & & & CIS & REFERENCE PERIOD \\
\hline 1 & 1977-1985 & & & \\
\hline 2 & 1986-1992 & & & \\
\hline 3 & $1991-1997$ & & & \\
\hline 4 & 1996-1999 & & & \\
\hline 5 & $1998-2001$ & & & \\
\hline 6 & $2000-2003$ & & & \\
\hline 7 & $2002-2005$ & & & \\
\hline 8 & 2004-2007 & 2004-2007 & CIS4 & 2002-2004 \\
\hline 9 & 2006-2009 & $2006-2009$ & CIS 2006 & 2004-2006 \\
\hline 10 & 2008-2011 & $2008-2011$ & CIS 2008 & $2006-2008$ \\
\hline 11 & 2010-2013 & 2010-2013 & CIS 2010 & $2008-2010$ \\
\hline 12 & $2012-2015$ & 2012-2015 & CIS 2012 & 2010-2012 \\
\hline
\end{tabular}


Acknowledgements An early version of this work was presented at the Annual Conference of the Italian Association of Political and Industrial Economics (SIEPI), Rome, January 31 - February 1, 2019. We thank the audience and in particular Maria Grazia Squicciarini for insightful suggestions. We also thank the editors of the Special Issue and two anonymous reviewers for their comments. The usual disclaimers apply.

Funding Open access funding provided by Scuola Superiore Sant'Anna within the CRUI-CARE Agreement.

\section{Declarations}

We comply with ethical standard.

Open Access This article is licensed under a Creative Commons Attribution 4.0 International License, which permits use, sharing, adaptation, distribution and reproduction in any medium or format, as long as you give appropriate credit to the original author(s) and the source, provide a link to the Creative Commons licence, and indicate if changes were made. The images or other third party material in this article are included in the article's Creative Commons licence, unless indicated otherwise in a credit line to the material. If material is not included in the article's Creative Commons licence and your intended use is not permitted by statutory regulation or exceeds the permitted use, you will need to obtain permission directly from the copyright holder. To view a copy of this licence, visit http://creativecommons.org/licen ses/by/4.0/.

\section{References}

Andrews D, Criscuolo C, Gal P (2016) The Best versus the Rest: The Global Productivity Slowdown, Divergence across Firms and the Role of Public Policy, OECD Productivity Group Working Paper

Archibugi D (2001) Pavitt's taxonomy sixteen years on: a review article. Econ Innov New Technol 10(5):415-425

Arundel A, Kabla I (1998) What percentage of innovations are patented? Empirical estimates for European firms. Res Policy 27:127-141

Arundel A, van de Paal G, Soete L (1995) Innovation Strategies of Europe's Largest Industrial Firms: Results of the PACE Survey for Information Sources, Public Research, Protection of Innovations and Government Programmes. Final Report, MERIT, June 1995. DG XII of the European Commission

Bettis RA, Ethiraj S, Gambardella A, Helfat C, Mitchell W (2016) Creating repeatable cumulative knowledge in strategic management: a call for a broad and deep conversation among authors, referees, and editors. Strateg Manag J 37(2):257-261

Bodas Freitas IM, Castellacci F, Fontana R, Malerba F, Vezzulli A (2017) Sectors and the additionality effects of R\&D tax credits: a cross-country microeconometric analysis. Res Policy 46(1):57-72

Breschi S, Malerba F, Orsenigo L (2000) Technological regimes and Schumpeterian patterns of innovation. Econ J 110(463):388-410

Castellacci F (2007) Technological regimes and sectoral differences in productivity growth. Ind Corp Chang 16(6):1105-1145

Castellacci F (2008) Technological paradigms, regimes and trajectories: manufacturing and service industries in a new taxanomy of sectoral patterns of innovation. Res Policy 39:1139.1158

Corrocher N, Malerba F, Montobbio F (2007) Schumpeterian patterns of innovative activity in the ICT field. Res Policy 36(3):418-432

Evangelista R (2000) Sectoral patterns of technological change in services. Econ Innov New Technol 9:183-221

Fontana R, Nuvolari A, Shimizu H, Vezzulli A (2012) Schumpeterian patterns of innovation and the sources of breakthrough inventions: evidence from a data-set of R\&D awards. J Evol Econ 22(4):785-810 
Fontana R, Nuvolari A, Shimizu H, Vezzulli A (2013) Reassessing patent propensity: evidence from a dataset of R\&D awards, 1977-2004. Res Policy 42(10):1780-1792

Freeman C, Louça F (2001) As time goes by: the information revolution and the industrial revolutions in historical perspective. Oxford University Press, Inc.

Hamermesh DS (2007) Replication in economics. Canadian Journal of Economics/Revue canadienne d'économique 40(3):715-733

Malerba F (2005) Sectoral systems of innovation: a framework for linking innovation to the knowledge base, structure and dynamics of sectors. Econ Innov New Technol 14(1-2):63-82

Malerba F, Orsenigo L (1995) Schumpeterian patterns of innovation. Camb J Econ 19(1):47-65

Malerba F, Orsenigo L (1996) Schumpeterian patterns of innovation are technology-specific. Res Policy 25(3):451-478

Malerba F, Orsenigo L (1997) Technological regimes and sectoral patterns of innovative activities. Ind Corp Chang 6(1):83-118

Malerba F, Nelson R, Orsenigo L, Winter S (2016) Innovation and the evolution of industries. Cambridge University Press, Cambridge

Mansfield E (1986) Patents and innovation: an empirical study. Manag Sci 32:173-181

Marsili O (2001) The anatomy and evolution of industries. Technological change and industrial dynamics. Edward Elgar, Cheltenham

Muma JR (1993) The need for replication. Journal of Speech, Language, and Hearing Research 36(5):927-930

Nelson R, Winter S (1982) An evolutionary theory of economic change. Belknap Press of Harvard University Press, Cambridge

Orsenigo L (1995) Technological regimes, patterns of innovative activities and industrial dynamics. A survey of empirical evidence and some theoretical models. Cahiers d'economie et sociologie Rurales 37:26-67

Pavitt K (1984) Sectoral patterns of technical change: towards a taxonomy and a theory. Res Policy 13(6):343-373

Pavitt K (1990) What we know about the strategic management of technology. Calif Manag Rev 32(3):17-26

Pavitt K, Robson M, Townsend J (1989) Technological accumulation, diversification and organisation in UK companies, 1945-1983. Manag Sci 35(1):81-99

Peneder M (2010) Technological regimes and the variety of innovation behaviour: creating integrated taxonomies of firms and sectors. Res Policy 39:323-334

Schumpeter JA (1911) The theory of economic development: an inquiry into profits, capital, credit, interest, and the business cycle. Harvard University Press, Cambridge

Schumpeter JA (1942) Capitalism, socialism and democracy. New York

Srholec M, Verspagen B (2012) The voyage of the beagle into innovation: explorations on heterogeneity, selection, and sectors. Ind Corp Chang 21(5):1221-1253

van Dijk M (2000) Technological regimes and industrial dynamics: the evidence from Dutch manufacturing. Ind Corp Chang 9(2):173-194

van Looy B, Vereyen C, Schmoch U (2015) IPCV8-NACE rev.2 update (version 2.0). Available at: https://ec.europa.eu/eurostat/ramon/documents/IPC_NACE2_Version2_0_20150630.pdf

Publisher's note Springer Nature remains neutral with regard to jurisdictional claims in published maps and institutional affiliations. 